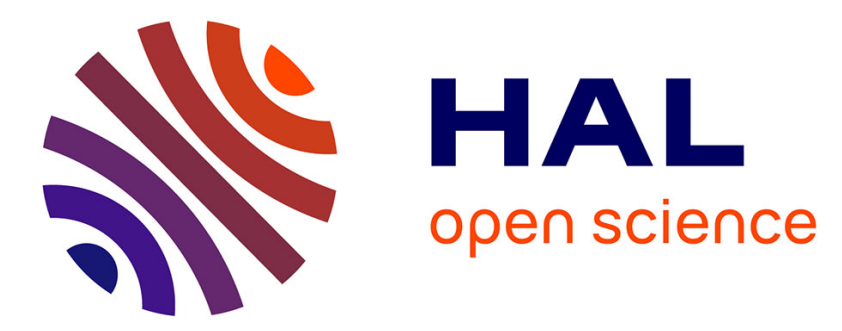

\title{
Information System as a Tool to Decrease the Economic Distortion in Trade Metrology
}

Bruno A. Rodrigues Filho, Mauricio E. Silva, Cláudio R. Fogazzi, Marcelo B. Araújo, Rodrigo F. Gonçalves

\section{- To cite this version:}

Bruno A. Rodrigues Filho, Mauricio E. Silva, Cláudio R. Fogazzi, Marcelo B. Araújo, Rodrigo F. Gonçalves. Information System as a Tool to Decrease the Economic Distortion in Trade Metrology. IFIP International Conference on Advances in Production Management Systems (APMS), Sep 2015, Tokyo, Japan. pp.121-128, 10.1007/978-3-319-22756-6_15 . hal-01417448

\author{
HAL Id: hal-01417448 \\ https://hal.science/hal-01417448
}

Submitted on 15 Dec 2016

HAL is a multi-disciplinary open access archive for the deposit and dissemination of scientific research documents, whether they are published or not. The documents may come from teaching and research institutions in France or abroad, or from public or private research centers.
L'archive ouverte pluridisciplinaire HAL, est destinée au dépôt et à la diffusion de documents scientifiques de niveau recherche, publiés ou non, émanant des établissements d'enseignement et de recherche français ou étrangers, des laboratoires publics ou privés.

\section{(c)(1)}

Distributed under a Creative Commons Attribution| 4.0 International License 


\title{
Information System as a Tool to Decrease the Economic Distortion in Trade Metrology
}

\author{
Bruno A. Rodrigues Filho ${ }^{1,3}$, Mauricio E. Silva ${ }^{1}$, Cláudio R. Fogazzi ${ }^{1}$, Marcelo B. \\ Araújo $^{2,3}$, Rodrigo F. Gonçalves ${ }^{3}$ \\ ${ }^{1}$ National Institute of Metrology, Quality and Technology - INMETRO, Duque de Caxias, \\ Brazil \\ ${ }^{2}$ Federal Institute of Education, Science and Technology - IFSP, São Paulo, Brazil \\ ${ }^{3}$ Paulista University - UNIP, São Paulo, Brazil \\ bafilho@inmetro.gov.br
}

\begin{abstract}
In economy, the amount of money due to an error of a measuring instrument used in trade is described as the economic distortion and this asymmetry is higher as the error involved. Repaired measuring instruments are responsible for a significant part of instruments used in the market. In Brazil, they are responsible for $64.8 \%$ of fuel dispensers and $21.1 \%$ of non-automatic weighing instruments used in trade, and they are subject to greater distortion once issues as impartiality and independence are involved in metrological control of these measuring instruments. In this study, an information system strategically aligned to legal control of measuring instruments was developed to map and identify repaired measuring instruments. Since the system implementation in 2012, an increase of $27.6 \%$ is observed in after repair verifications of fuel dispensers and $104.8 \%$ for non-automatic weighing instruments, contributing to decrease economic distortion in trade.
\end{abstract}

Keywords: Economics, legal metrology, market asymmetry, information technology.

\section{Introduction}

Legal metrology is a specific field in the science of measures, where regulations are applied on measurements, determining required characteristics and methods in measuring instruments that are relevant to a measure. Regulations change according to each country necessity however they are usually applied, in metrology, to instruments where trade, health and safety are involved [1].

Specifically in trade, the consumers have no means to check the amount of goods that is being traded, leading to an unfair competition as well as to consumer's protection issues [2], consequently leading to a lack of confidence undermining the relationship between consumers and suppliers. The impact of measuring instruments can be significant to a country, affecting a significant part of its Gross Domestic Product (GDP) [3]. The economic impact of measuring in trade can be realized in studies carried out in USA in 1996 that showed that measures represent the amount of $54.5 \%$ of the GNP [4], and more recently in the United Kingdom where goods which value is 


\section{B. A. Rodrigues Filho et al.}

based on a measure represented $£ 622$ billion in 2002 [2]. Impact studies have also presented that an average of $0.1 \%$ error in measures would represent $0.05 \%$ of GDP [5]. The substantial impact of measurements in the GDP of a country demonstrates the importance of developing tool to improve legal metrology control.

The legal control of measuring instruments is the tool used in legal metrology to maintain under control this asymmetry, using verifications and surveillance activities to keep these errors according to established in regulations.

This market asymmetry, i.e. the economic distortion between what is being traded and the measurement indicated by an instrument, indicates the monetary unit attached to an error in a measuring instrument [6]. In the macro economic scenario this indicator allows to obtain the amount of money under uncertainty due to measuring errors. This distortion is considerate one of the causes that can fail a market, where increasing accuracy of the metrology system increases the economic return [7], so an efficient way to decrease the economic distortion is vital to improve a nation economy. Moreover, the main aspect of the economic distortion indicator is to be a monetary representation of measuring errors, allowing comparisons among countries.

Repaired measuring instruments represent a significant number of instruments used in trade, as an example, in Brazil, 276,464 fuel dispensers were repaired in 2013, representing $64.8 \%$ of total and $21.1 \%$ of the $1,401,510$ non-automatic weighing instruments in use [8]. The repaired instrument is an important part of the legal metrology control because when an instrument in the marked is repaired, its metrological performance is affected and a complementary verification, defined as after repair verification is necessary to attest if the errors are according to regulations, keeping the market under control. The commercial relationship involving repaired measuring instruments involves impartiality and independence issues once a body responsible for the repair evaluates its own service.

In order to decrease the economic distortion in trade due to repaired measuring instruments the present study aims to implement an information system align strategically to be used as a tool to decrease this asymmetry in repaired measuring instruments under the legal metrology control.

\section{The Control of Measures in Trade}

In most countries, metrology is centralized in a National Metrology Institute (NMI), responsible for regulation in legal metrology and maintenance of the national standards and laboratorial infrastructure to dissemination of traceability [1].

The activities to control the measuring instruments can be divided in three different levels [9]:

- Type approval an initial verification - Type approval comprehends the compliance of instrument features according to the regulations, before its production; and initial verification represents the assessment of the instrument, according to its legal requirements, after it is manufactured. Both are conducted before the instrument is put in the market. 
- Periodic and after repair verification - Regulated measuring instruments are verified regularly in the market to attest the continuous attendance of the instrument to the legal requirements. After a repair, the instruments are also verified, once it may cause influence over its performance, affecting its reliability.

- Surveillance - This level represents the control of instrument in use in the market applied to identify frauds and misuses of regulated measuring instruments.

These actions in legal metrology are named as the legal metrological control activities and must be conducted in order to keep the reliability of measures in trade.

The NMI can delegate the verification and repair activities to notified bodies to either private or public bodies, as in France, where verifications are carried out by both public and private notified bodies [10] and in Brazil where verifications are executed exclusively by public bodies [11].

Another relevant aspect that must be pointed regards the repairs performed in measuring instruments by notified bodies. There are two approaches regarding a repair in a measuring instrument: the body responsible for the repair conducts the verification; or the NMI carries out the verification after the repair is executed. In the first case, there is a lack of impartiality once the body verifies its own repair. In the second situation despite after repair verification carried out by a third independent body, the measuring instrument is still in use right after the repair for an indeterminate period. This period depends on the infrastructure of the NMI to perform the after repair verification as soon as possible. Also, it is not possible to predict when or where a repair is going to be demanded. This aspect is vital to countries with large territories.

\section{Information Systems}

Information systems (IS) were introduced in organizations mainly to support managers [12]. The concept of an information system involves not only technical aspects of a system as the software or hardware, but also all the information flow, i.e. data and human resources [13].

The aspects of developing an information system are wider than developing software or a platform as it also incorporates human, administrative and organization aspects [14].

Strategy is also a significant component of success to implant an information system inside an organization. The misalignment between the organizations and IS strategies may lead to the inefficiency of the IS when compared to its full potential [15]. Consequently, to have full benefits of an efficient information system, the organization should be strategically aligned to the information system to be implemented [16].

Regarding the insertion of IS inside an organization, development of data process can be divided into six stages: initiation (I); contagion (II); control (III); Integration (IV); data administration (V); maturity (VI). The managing action to the progress of the IS starts with the initiation of the system within the organization passing throw contagion, control, integration, data administration concluding in the maturity stage. According to this model, the first stage represents the initialization of the system inside the organization, the users are not concerned about the system and the control is 
4 B. A. Rodrigues Filho et al.

considered lax. As the system evolves inside the firm, in stage three (control), the management moves from the computer management to data resources management. In the final stage of growth, the system application is considered mature and the managements are focused on information flow [17].

In addition, the IS when properly lined up to the strategic requirements of the organization contributes to innovation [18].

\section{$4 \quad$ Methodology}

The system used to control repaired measuring instruments was incorporate in a specific website named PSIE - Portal de Serviços do Inmetro nos Estados (Platform of Services of Inmetro in States, literally). For simplicity, the system will be called hereinafter PSIE. The platform can be accessed in the link http://servicos.inmetro.rs.gov.br, and allowed to identify the location and the technical specifications of repaired measuring instruments. The authors were involved in establishing the requirements to the system according to legal metrology requirements in Brazil, coordinate the programmers' team, as well as to analyze the results in order to verify its impact in the after repair verifications.

In order to initiate a mandatory activity in legal metrology, a regulation development is necessary. Thus the project was divided into three well-defined steps:

- Step 1. Launching the system as voluntary for fuel dispensers in August 2012, in order to identify possible problems;

- Step 2. Developing and implementing regulation for bodies that execute repairs in fuel dispensers, issued in January 2013;

- Step 3. Expanding the regulation (to be issued in 2015) to notified bodies that provide repairs to measuring instruments used in trade (non-automatic weighting instruments, taximeters, length measuring instruments, and measuring systems for gaseous fuel).

The control of repaired fuel dispenser was set as a priority due to fraud events related to this instrument [19]. It would also be used as a test case to point out failures in the system, allowing improvements to the system to be applied to other instruments. Despite the regulation to be issued in 2015, the system is available since January 2013 as voluntary to non-automatic weighing instruments (NAWI).

No comparisons to other countries were conducted, once similar studies were not available, according to systematic literature review carried out in the legal metrology control [20].

\subsection{Strategy Alignment}

In order to develop the system that will monitor repaired measuring instruments used in trade, the strategic alignment between Inmetro (National Institute of Metrology, Quality and Technology), the Brazilian NMI, and the system was explored. Inmet- 
ro strategic guidelines are available for consult in the link: http://www.inmetro.gov.br/english/institucional/index.asp.

According to Inmetro strategy, the system has been developed to meet the necessities in metrology regarding competitiveness, fair competition and consumers' protection since its main objective is to decrease the economic distortion due to increase of after repair verification.

\subsection{Using the Platform}

When a bodied is notified by the NMI to be responsible for repairs in measuring instruments, it gets, for each technician, a unique password to access the platform. After a repair, the technicians have a five days deadline to inform the specifications of the repair, measuring instrument information, and address in the platform (as serial number, ID, number of type approval certificate and sealing marks). This deadline period was chosen due to regional aspects of Brazil, once it is a continental country and internet connection problems may occurs in remote regions.

The bodies responsible for verifications conduct after repair verifications using the information provided by the notified body, as well as the surveillance over the usage of the platform by the notified bodies.

\section{$5 \quad$ Results and Discussion}

A three level curve was obtained, where first level (A) represents the understanding and initialization of the system followed by a fast growth (second level) as the use of the system becomes more frequent (B), and finally a stabilized behavior where the number of repair fluctuates around an average (C). According to the six stages of processing growth, first level (A) of curve in figure 1 can be interpreted as stage I, which means the initialization of the system. Step two (B) is related to stage II and III as PSIE use proliferated and regulation was implemented. In step three $(C)$, the curve stabilizes and integration of repairs and after repairs verification is implemented representing stage IV. Data managing and full use of the system, including not only repairs in fuel dispensers would represent stages V and VI, and are next step to be achieved by the PSIE. The organization in this case can be interpreted as a composition of the National Metrology Institute and bodies responsible for repairs.

Figure 1 shows the number of repairs informed to the PSIE for fuel dispensers. The first level (A) can be observed from August (2012) - February (2013), second level (B) from February-April (2013) and third level (C) after April (2013), where repairs float around an average of 25,050.

For NAWI, a fast growth of the curve is not observed, regarding its voluntary use until 2015. A Pearson correlation coefficient $\rho=0.6713$ characterizes the curve as still in the first level (A). A fast growth, similar to fuel dispenser repair, is expected during 2015 due to mandatory aspects of the PSIE to NAWI.

In 2012 (August-December) 87,740 repairs in fuel dispensers were informed in PSIE, in 2013 276,464 (January-December) repairs were informed and finally in 2014 
6 B. A. Rodrigues Filho et al.

that number increased to 315,013 . For non-automatic weighing instruments, 295,624 repairs were informed in 2013 (January-December) and from January to December 2014 it increased to 405,668. A superior number of repairs in NAWI are expected when compared to fuel dispenser since $1,384,825$ verifications were executed in NAWI compared to 363,803 in fuel dispensers, in 2014.

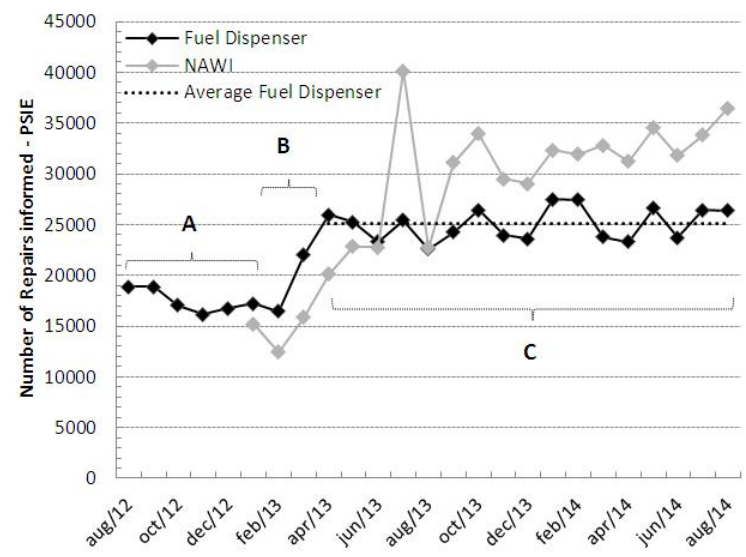

Fig. 1. Repairs informed to the PSIE by notified bodies for fuel dispensers from August 2012 to December 2014.

The number of after repair verifications in fuel dispensers and NAWI is exhibited in figure 2.

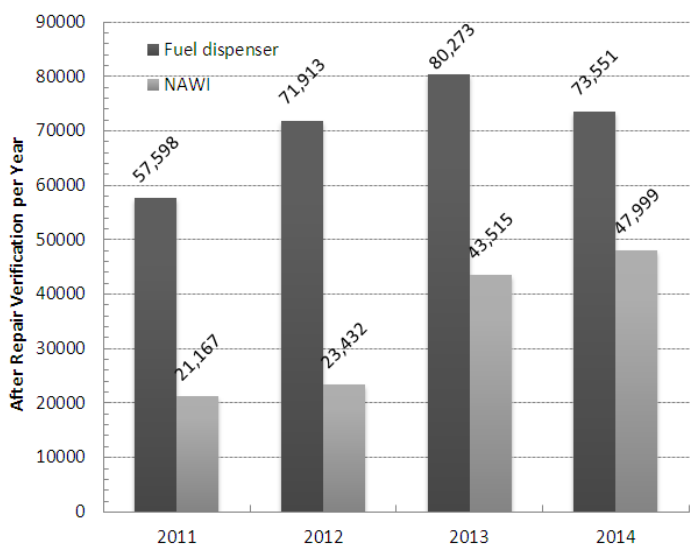

Fig. 2. After repair verification for fuel dispensers and non-automatic weighing executes from 2011 to 2014.

For fuel dispensers, an increase from 57,598 to 71,913 (24.8\%) comparing 2012 to 2011 and from 71,913 to 80,273 (11.6\%) in after repair verifications comparing 2013 
to 2012 . In 2014 it decreased from 80,273 to 73,551 is observed due to external aspects, once periodic verifications decreases $17.22 \%$ as well. However, since the system implantation, comparing 2014 to 2011, an expansion from 57,598 to 73,551 $(27.6 \%)$ is observed for after repair verifications for fuel dispensers.

Regarding after repair verification in NAWI, a growth from 23,432 to 43,515 (85.7\%) comparing 2013 to 2012, and a growth to 47,999 (10.3\%) comparing 2014 to 2013 However, as the PSIE was implemented as voluntary in 2013, an increase $104.8 \%$ from 2012 to 2014 is contemplated in NAWI.

As a consequence of after repair verifications, 6,300 fuel dispensers and 4,417 NAWI (considering accuracy class III and IV, up to $1,500 \mathrm{~kg}$ capacity) were rejected and were withdrawn of use in 2014.

\section{Conclusions}

The system presented in this study has shown an important tool to legal metrological control. After the implementation of PSIE, in 2012, an abrupt increase of $24.8 \%$ was observed in after repair verification in fuel dispensers comparing to 2011 . And an increase of $27.6 \%$ is observed comparing 2014 to 2011 .

Legal aspects were also a vital component to PSIE to succeed. It can be observed since the performance of the system has not shown the same efficacy to nonautomatic weighing instruments when compared to fuel dispensers mainly because the PSIE is not mandatory to NAWI however a significant growth of $104.8 \%$ in after repair verification in observed from 2012 to 2014.

The impact to the consumers can be realized in the 6,300 fuel dispensers and 4,417 NAWI rejected and withdrawn from market in 2014. Despite this significant result, a stable number of repairs to NAWI are still desirable. However, it can be interpreted that the system has been vital to this result.

Strategic alignment of PSIE to legal metrology, incorporating legal aspects in the regulation was also an important goal for the system, once three well-defined steps can be observed after the system implantation. Also, according to the six stages of growth of data processing in an organization, in this case an organization is composed of the NMI and bodies responsible for repairs, it can be conclude that the system is between stages III and IV, where proliferation and data processing are in course.

Finally, due to the increase of after repair verifications, inaccurate instruments are withdrawn from the market, consequently decreasing the economic distortion in the commerce. Once measuring instruments used in trade are according to regulation, they lead to fair competition, consumer's protection, contributing to the economic development.

It can be concluded that the PSIE has achieved its main objective since the increase of after repair verifications is responsible for decrease economic distortion once an abrupt growth is verified in after repair verifications for fuel dispensers. For NAWI this behavior has not been observed, mainly because of voluntary use of PSIE, However, a similar performance is expected after 2015. 
8 B. A. Rodrigues Filho et al.

\section{Acknowledgement}

The authors acknowledge the support of INMETRO, which enabled us to carry out this research.

\section{References}

1. De Silva, G.M.S.: Development of metrology in developing economies. OIML Bull. XLVII, 13-20 (2006).

2. Sanders, R.: Why do we regulate measuring instruments used for trade. OIML Bull. LII, $13-15$ (2011).

3. Carstens, S.: AFRIMETS (Intra-Africa Metrology System). OIML Bull. LI, 5-10 (2010).

4. Ardianto, R.: A way to stimulate public awareness. OIML Bull. LII, 33-38 (2012).

5. Birch,J.:Economic and Social Benefits of Legal Metrology.OIMLBull.XLV,10-13 (2004).

6. Birch, J.: Benefit of legal metrology for the economy and society - A study for the International Committee of Legal Metrology. International Organization of Legal Metrology OIML, Paris, France (2003).

7. Swann, P.: The economics of metrology and measurement. National Measurement Office, United Kingdom (2009)

8. Rodrigues Filho, B.A., Silva, M.E., Gomes, L.C., Soratto, A.N., Gonçalves, R.F.: Enhancements of the legal metrological control in Brazil due to after repair verification. 9th International Symposium "Metrologia 2014" Proceedings. p. 8. , Havana, Cuba (2014).

9. Klenovsky, P.: Legal metrological control over measuring instruments in use: current situation. OIML Bull. XLVII, 22-33 (2006).

10. Lagauterie, G.: The evolution of the metrological control of measuring instruments in France. OIML Bull. XLV, 25 - 31 (2004).

11. Silva, P.P.A., Réche, M.M.E., Silva, M.E.: The legal metrology Brazilian model. Presented at the XVIII IMEKO World Congress - Metrology for a Sustainable Development, Rio de Janeiro, Brazil (2006).

12. Gupta, Y.P.: Management information systems planning: analysis and techniques. Technovation. 9, 63-81 (1989).

13. Alter, S.: Information Systems: a management perspective. Addison-Wesley Publishing Co. Massachusetts (1992).

14. Keen, P.G.W.: Information Technology And The Management Theory: The Fusion Map. IBM Syst. J. 32, 17-38 (1993).

15. Henderson, J.C., Venkatraman, N.: Strategic Alignment: Leveraging Information Technology For Transforming Organizations. IBM Syst. J. 32, 4-16 (1993).

16. Luftman, J.N., Lewis, P.R., Oldach, S.H.: Transforming the enterprise: The alignment of business and information technology strategies. IBM Systems Journal. 32, 198-221 (1993)

17. Nolan, R.L.: Managing the Crises in Data Processing. Harv. Bus. Rev. 115-126 (1979).

18. Yang, M.L., Wang, A.M.-L., Cheng, K.C.: The impact of quality of IS information and budget slack on innovation performance. Technovation. 29, 527-536 (2009).

19. Brandão, P.: Contramedidas de hardware y software sobre el fraude de alta tecnología al Surtidor de combustible bajo el alcance de Metrología Legal. 9th International Symposium "Metrologia 2014" Proceedings. p. 8. , Havana, Cuba (2014).

20. Rodrigues Filho, B.A., Gonçalves, R.F.: Legal metrology, the economy and society: A systematic literature review. Measurement. 69, 155-163 (2015). 